\title{
EFFECT OF ALKALINE LIQUID RATIO ON THE COMPRESSIVE STRENGTH OF GEOPOLYMER CONCRETE
} (A THEORETICAL APPROACH)

\author{
D. Annapurna ${ }^{1}$, Ravande Kishore ${ }^{2}$, G.Vikas ${ }^{3}$ \\ ${ }^{1}$ Assistant Professor, Civil Engineering Department, UCE (A), Osmania University \\ ${ }^{2}$ Professor of Civil Engineering Department, UCE (A), Osmania University \\ ${ }^{3}$ M.E scholar, Civil Engineering Department, University College of Engineering, Osmania University, Hyderabad- 07
}

\begin{abstract}
Carbon dioxide $\left(\mathrm{CO}_{2}\right)$ emission into the atmosphere is a factor for the cement industries, as the green house effect created by emission is considered to produce an increase in global temperature that may result in climate change. The use of concrete is increasing worldwide in a fast track and therefore the development of suitable concrete is expected for environmental reasons and for strength parameter. Replacement of cement with Geopolymer is one of the efforts to produce more environmentally friendly concrete. No cement is used in Geopolymer concrete, but fly ash and alkaline solutions, i.e, sodium hydroxide (Na OH) and sodium silicate $\left(\mathrm{Na}_{2} \mathrm{O}, \mathrm{SiO} 2\right)$ are used to make the binder necessary to manufacture the concrete. To produce 2.5 cubic meter of high quality Geopolymer concrete, One tone of fly ash can be utilized. In this study investigations are made to see the effect of Alkaline liquid to fly ash ratio on compressive strength of Geopolymer concrete in ambient conditions as well as oven dry conditions at $90^{\circ}$ for 4 hours. Alkaline liquid ratio is varied from 0.5 to 0.3 and compressive strengths are detected after 7 and 28 days. A mathematical model is prepared by using the Fuzzy logic to predict the compressive strength of Geopolymer concrete for different chemical ratios using the experimental results. The alkaline liquid ratio is used as input and 7 days, 28 days and oven dried samples compressive strengths are used as output while developing Fuzzy logic model. Compressive strength of Geopolymer concrete depends on proportioning of ingredient of mix design. Fuzzy logic model can be effectively used to replace the experimental work. To develop the model, part of the experimental data is used for Training \& Testing and remaining part for validating the results.
\end{abstract}

Keywords: Geopolymer Concrete, Fuzzy Logic model, Compressive strength.

$$
\text { ****.. }
$$

\section{INTRODUCTION}

The most widely used construction material is concrete. By partially replacing cement with fly ash the unit cost of concrete can be reduced. The fly ash disposal is one of the major issues for environmentalists, because dumping of fly ash as waste material causes severe environmental problems. Instead of dumping fly ash as a waste material, partly it can be used on economic grounds as pozzuolana for partial replacement of cement and partly because of its useful effects of lower water demand for workability, reduction in bleeding and lower heat evolution. It will be used particularly in mass concrete applications and large volume placement to control expansion due to heat of hydration and also helps in reducing cracking at early ages.

Because of improved qualities, Fly ash based Geopolymer concrete can be used widely for any construction purpose. If Geopolymer concrete is used in constructing floors and walls, then it gives a glossy surface that can give a good appearance. Flyash based Geopolymer concrete fire resistance properties and resistance against abrasion with alkali activation when compared to that of Ordinary Portland Cement. As fly ash is only a by product material found from industrial wastes cost of such Geopolymer concrete is less than or at most equal to OPC concrete which uses expensive cement as binder material.
Davidovits from France first used the term Geopolymer concrete and proposed that an alkaline liquid could be used to react with the silica and the Alumina in the geological source material or in by-product materials like fly ash, rice husk ash to produce binders. The geopolymer materials chemical composition is similar to natural Zeolitic materials, but this has amorphous microstructure. Based on the Silica to alumina atomic ratio present in the polymers, the geopolymers are widely used in Bricks, fire protection works ,ceramics, in low $\mathrm{CO}_{2}$ cements manufacturing, concretes radioactive and toxic waste encapsulations, and fire protection fiber glass composites etc.

The application of Mat lab is high level language that includes matrix based data structures, its own internal data an extensive function catalog, an environment in which to develop your own functions and scripts, import ability and export to many data files. In Mat lab, Fuzzy logic tool box we have member function, which play an important role for output parameter. The Mathematical model using Fuzzy logic is developed in Mat lab to replace the experimental work. The obtained results with Fuzzy logic model were compared with the experimental results and found remarkably close to each other. 


\section{EXPERIMENTAL INVESTIGATION}

The material used in mixing of Geopolymer concrete as follows:

\section{Fly Ash:}

According to the ACI, fly ash is defined as "the finely divided residue that resulted from the combustion of ground or powdered coal and that is transported by flue gasses from the combustion zone to the particle removal system". The Fly ash particles are typically spherical, finer than Portland cement and line ranging in diameter from less than 1 micron to no more 150 microns. The chemical composition of fly ash is determined by types and relative amount of incombustible matter in the coal. Fly ash used in this study was dry fly ash procured from the Ramagundam thermal project. The sample of the fly ash was sent to Indian Institute of Chemical Technology at Taranaka, Hyderabad, India and the chemical composition of the fly ash has been found out.

\section{Aggregates}

The aggregates used in the mix met with the requirements of conventional concrete using OPC. Local aggregates, comprising coarse aggregates of size $20 \mathrm{~mm}, 14 \mathrm{~mm}$ and 7 $\mathrm{mm}$ and fine aggregates, in saturated surface dry condition (SSD) condition were used.

\section{Alkaline Liquid}

The alkaline liquid used was a combination of sodium silicate solution and sodium hydroxide solution. The sodium silicate solution $\left(\mathrm{Na}_{2} \mathrm{O}=13.7 \%, \quad \mathrm{SiO}_{2}=29.4 \%\right.$, and water $=55.9 \%$ by mass) was purchased from a local market in bulk. The sodium hydroxide $(\mathrm{Na} \mathrm{OH})$ in flakes or pellets from with $97 \%-98 \%$ purity was also purchased from a local market. The $\mathrm{Na} \mathrm{OH}$ flakes were dissolved in water to make the solution with required molarity

\section{Super Plasticizer}

SP 420 super plasticizer is used.

\section{MIX PROPORTIONS}

An extensive study on the development and the manufacture of fly ash based Geopolymer concrete was done at Curtin University Australia. Based on that study, different mixture proportions were formulated for making concrete specimens. The role and influence of the aggregates are considered to be the same as in the case of OPC concrete. The process of selecting the required mixture proportion has been adopted from a similar approach used in the case of OPC concrete.

Concrete mix design is vast and generally based on the performance criteria. An extensive study on the development and the manufacture of fly ash based geopolymer concrete was done at Curtin University Australia. Based on the study, different mixture proportions were formulated for making concrete specimens. The aggregates are selected from granite stone i.e., granite chalks as coarse aggregate and $\mathrm{M}$-sand as fine aggregates. The process of selecting the required mixture proportion has been adopted from a similar approach used in the case of OPC concrete. The mixture proportions per one $\mathrm{m}^{3}$ of Geopolymer concrete for 5 chemical ratios $(0.5,0.45,0.4$, $0.35,0.3)$ are given in mix design chart appended to the report. 15 cubes are casted for each chemical ratio variation.

\section{MANUFACTURING OF TEST SPECIMENS}

\subsection{Preparation of Alkaline Liquid}

The sodium hydroxide $(\mathrm{Na} \mathrm{OH})$ flakes were dissolved in water to make a solution. The mass of $\mathrm{NaOH}$ solids in a solution varies depending on the solution concentration expressed in terms of molar M. The sodium silicate solution and the sodium hydroxide solution were mixed together one day prior to use to prepare the concrete. The chemical mix can be kept up to 48 hours also. On the day of casting of the specimens, the alkaline liquid would be mixed with extra water (if any) to prepare the liquid component of the mixture for better workability.

\subsection{Procedure for Mixing and Casting of} Geopolymer Concrete

The mixing procedure plays a vital role in the production of Geopolymer concrete to the unstable nature of some mixes. If constituents are added in the wrong (it possible that the concrete fly ash may set in the mixer, causing both a trail mix tough clean up. For this reason, a particular order was followed in the concrete mixing, during this research. The moulds were first prepared for concrete pouring by coating them with some grease and a paper was placed on the inner surface of the mould. The alkaline solution consisting of sodium hydroxide and sodium silicate was combined at the beginning of the day when producing concrete. This is done in order to avoid the solution crystallizing over a long stationary period, an outcome that would deem the concrete mix design to differ if water was used to dissolve the solid again. The sodium hydroxide solution was added carefully to the second constituent and mixed thoroughly, before being sealed with lids prior to mixing time.

The mixing procedure for Geopolymer concrete was similar to that of conventional OPC concrete. All dry aggregates and fly ash were added and mixed for a few minutes to properly combine all sizes. After this dry mixing, the alkaline solution and any extra water and super plasticizer was then added gradually and then mixed for a further three minutes or till the adequate mixture is formed. The produced Geopolymer concrete differed physically to ordinary Portland cement concrete. The Geopolymer concrete mixture is shown in figure1.Geopolymer concrete is very dark in color and has an extremely "sticky" nature.The placement of the concrete into cubes therefore took longer than expected due to the difficulty of moving the concrete after mixing. It was observed that the workability is zero as there is no slump. Moulds were filled to approximately half 
way before being vibrated for a few minutes or until no bubbles were being formed at the surface. The cylinder was then filled to top and vibration started again, each mould being topped up and the vibration caused the elimination of any air voids. Upon completion of the concrete placement, cylinders were moved from the table to an area in the labs for setting under ambient conditions.

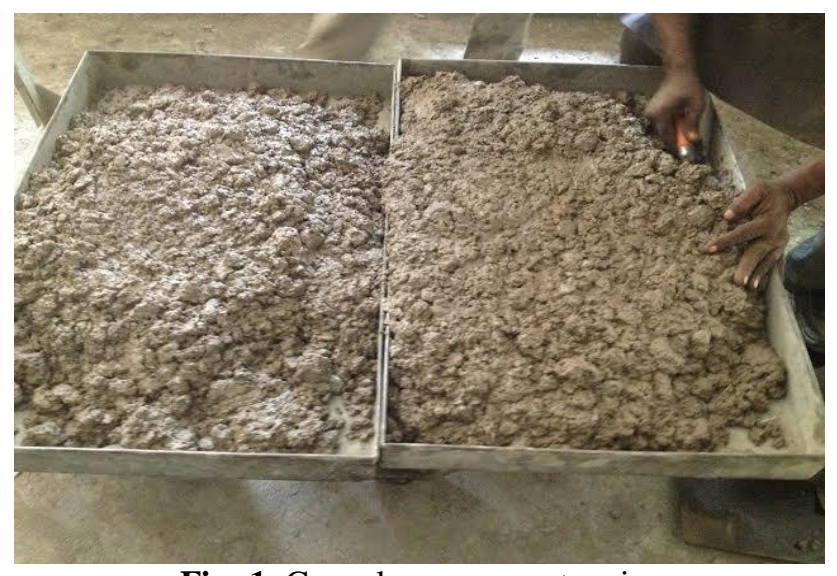

Fig -1: Geopolymer concrete mix.

\subsection{Testing of Specimen}

Compressive strength test was conducted for cube moulds of 150 X 150 X $150 \mathrm{~mm}$ size for 7 days and 28days strength.

\section{TEST RESULTS AND DISCUSSIONS}

\subsection{Compressive Strength}

The casted specimens are demoulded after 24 hours and immediately kept in ambient temperature. For each alkaline liquid ratio, 3 cubes are kept in dry oven for 4 hours continuously at $90^{\circ} \mathrm{C}$ immediately after demoulding and tested for compressive strength. The specimens kept in ambient temperature are tested for 7 and 28 days compressive strength. It is placed on the machine such that the load is applied centrally. The smooth surface of the specimen is placed as the bearing surface. The top of the plate is brought in contact with the specimen by rotating the handle. The oil pressure valve is closed and the machine is switched ON. A uniform rate of loading $1401 / \mathrm{sq} \mathrm{cm} / \mathrm{min}$ is maintained. The maximum load at failure at which the specimen breaks and the average value is taken as the mean strength. The compressive strength is taken as the mean strength divided by the area of the load bearing surface of the specimen (P/A). Compressive strength results of Geopolymer concrete are shown in Table-1

Table -1: Compressive strength results of Geopolymer concrete

\begin{tabular}{|l|l|l|l|l|}
\hline $\begin{array}{l}\text { Cube } \\
\text { Name }\end{array}$ & $\begin{array}{l}\text { Alkaline- } \\
\text { liquid } \\
\text { Ratio }\end{array}$ & $\begin{array}{l}\text { Oven } \\
\text { Strength } \\
\text { in Mpa }\end{array}$ & $\begin{array}{l}\text { Compressive } \\
\text { Strength for } \\
\text { 7days in Mpa }\end{array}$ & $\begin{array}{l}\text { Compressive } \\
\text { Strength for } \\
\text { Mpa days in } \\
\text { Ga }\end{array}$ \\
\hline $\mathrm{G}_{0.5}$ & 0.5 & 31.52 & 18.75 & 28.55 \\
\hline
\end{tabular}

\begin{tabular}{|l|l|l|l|l|}
\hline $\mathrm{G}_{0.45}$ & 0.45 & 28.75 & 17.1 & 27.07 \\
\hline $\mathrm{G}_{0.4}$ & 0.4 & 25 & 15.8 & 24.7 \\
\hline $\mathrm{G}_{0.35}$ & 0.35 & 23 & 14.5 & 23.2 \\
\hline $\mathrm{G}_{0.3}$ & 0.3 & 21.3 & 13.2 & 22 \\
\hline
\end{tabular}

\subsection{Development of Fuzzy Logic Model and Result}

This is the second phase of investigation. In the development of the fuzzy logic model 75 experimental results are used. The part of data used for testing \& training and remaining for validating the results. In the Mat lab Fuzzy logic tool box, input is considered as alkaline liquid ratio and output as compressive strength (MPa) and same is shown in the table 5.6.

Based on earlier studies, the Triangular membership form is selected in the model generation. Fuzzy logic mainly depends on "IF-THEN RULES", therefore creation of rules depends on experiment. Input alkaline liquid ratio varies from 0.5 to 0.3 and output compressive strength varies from 18 to $32 \mathrm{Mpa}$. Input and output variation is divided into different part i.e. very low, low, medium, high, and very high. As per logic thinking rules are created i.e. If alkalineliquid ratio is very low then 7 day compressive strength is med, 28 day compressive strength is high and oven compressive strength is very high. Input membership form is shown in the fig. 3 and output membership forms are shown from fig.4 to 6. After forming rules, fuzzy logic results are obtained using defuzzification centroid method and are shown in fig 7 to 10 .

Table 2: The Range of Input and Output Parameters used in Fuzzy model.

\begin{tabular}{|l|l|l|l|}
\hline \multirow{2}{*}{$\begin{array}{l}\text { Input } \\
\text { (Alkaline- } \\
\text { liquid Ratio) }\end{array}$} & \multicolumn{3}{|l|}{ Output (Compressive strength in MPa) } \\
\cline { 2 - 4 } & 7 days & 28 days & Oven \\
\hline 0.5 to 0.45 & $18.7-17.1$ & $28.5-27.07$ & $31.5-28.7$ \\
\hline 0.45 to 0.4 & $17.1-15.8$ & $27.07-24.7$ & $28.75-25$ \\
\hline 0.4 to 0.35 & $15.8-14.5$ & $24.7-23.2$ & $25.1-23$ \\
\hline 0.35 to 0.3 & $14.5-13.2$ & $23.2-22$ & $23-21.3$ \\
\hline
\end{tabular}




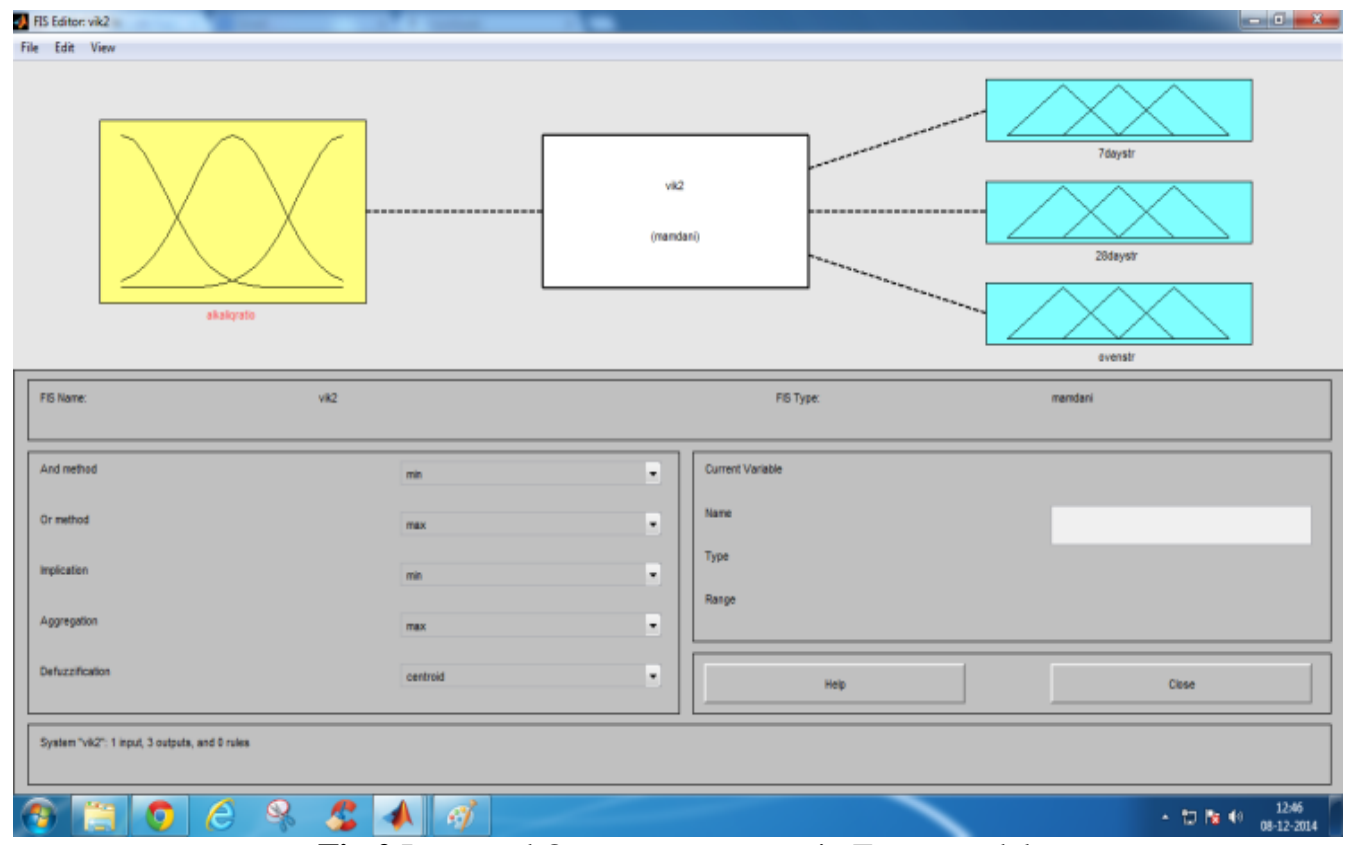

Fig.2 Input and Out put parameters in Fuzzy model

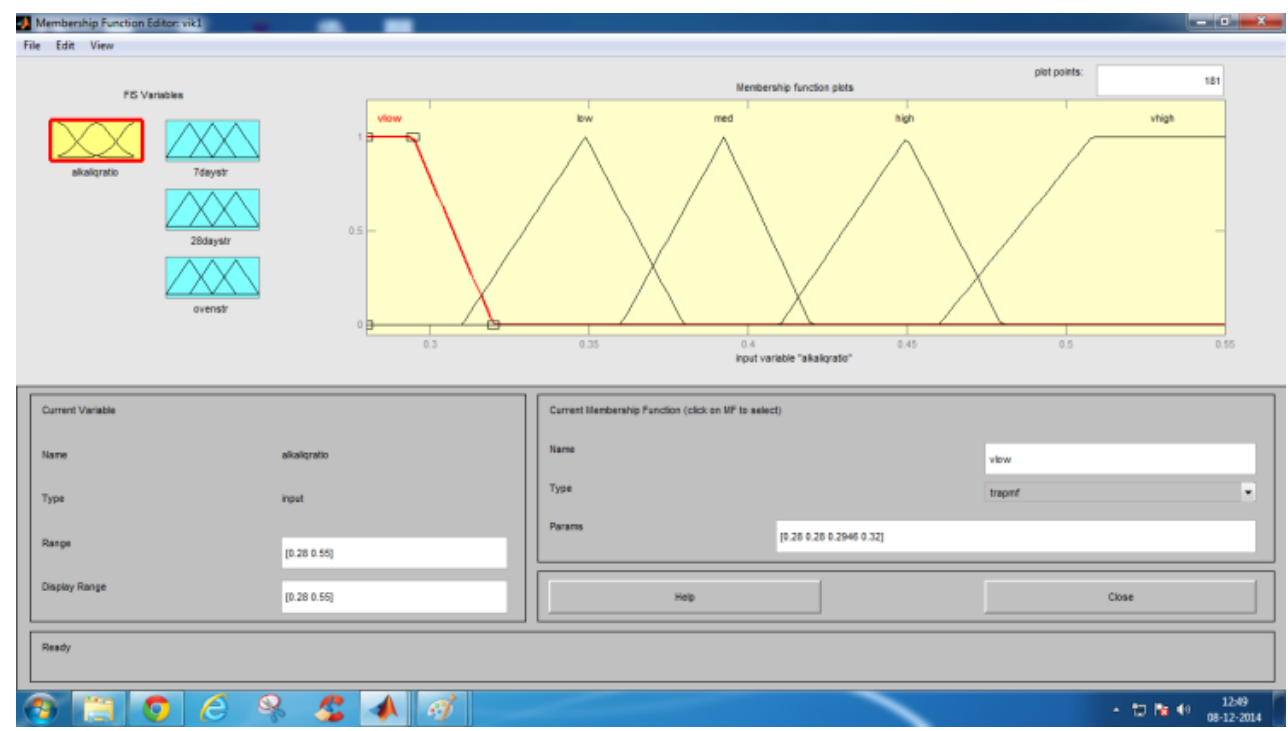

Fig 3. Membership form for input (Alkaline liquid ratio)

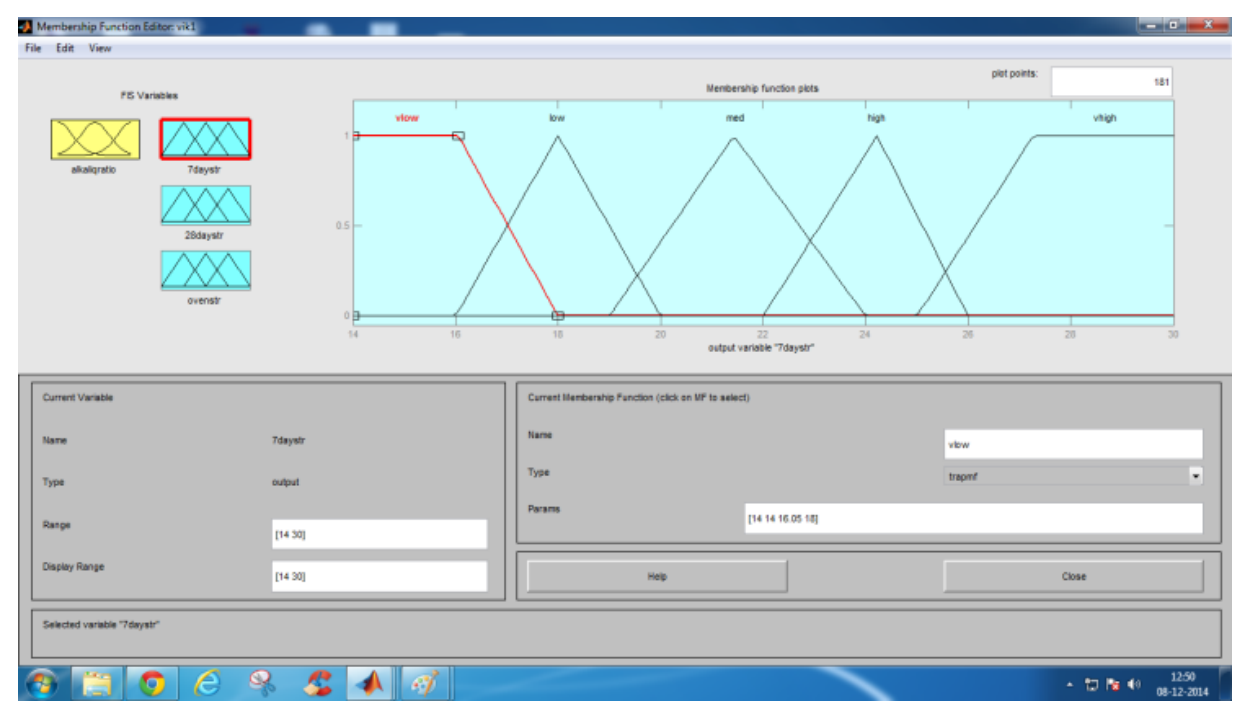

Fig 4. Membership form for output (7 day compressive strength) 


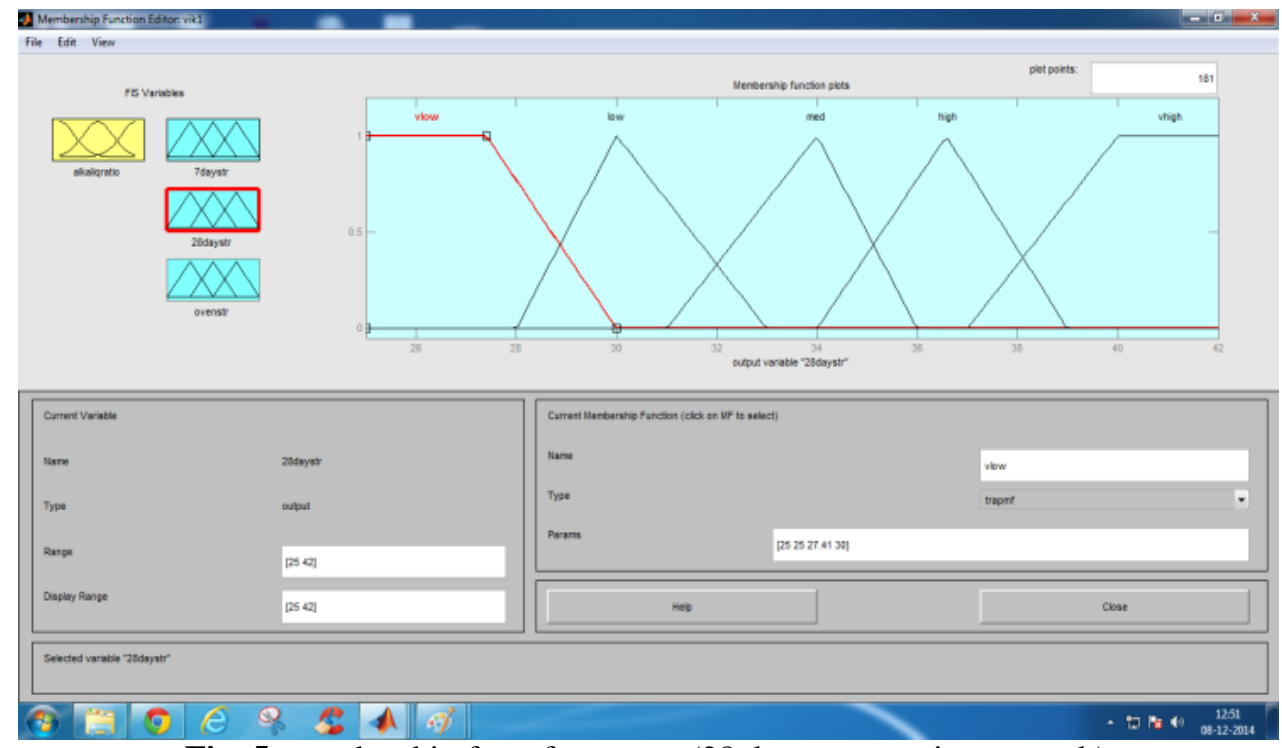

Fig. 5. membership form for output (28 day compressive strength)

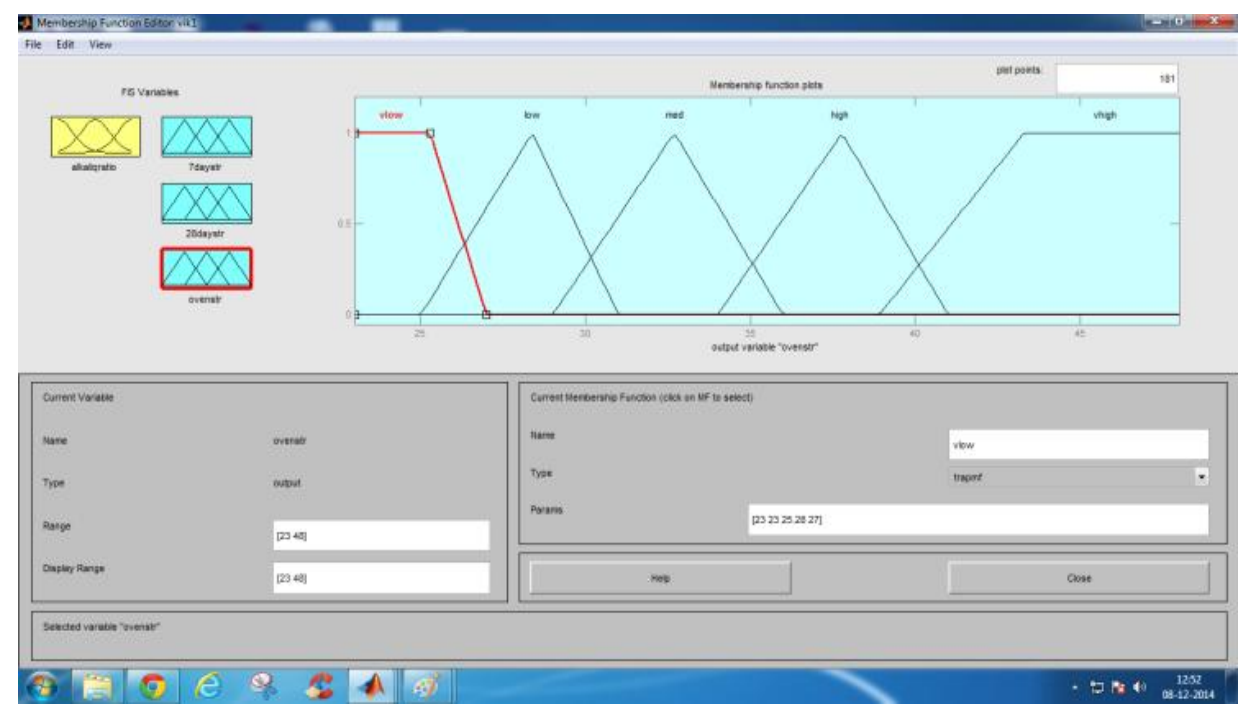

Fig. 6. Membership form for output (oven compressive strength)

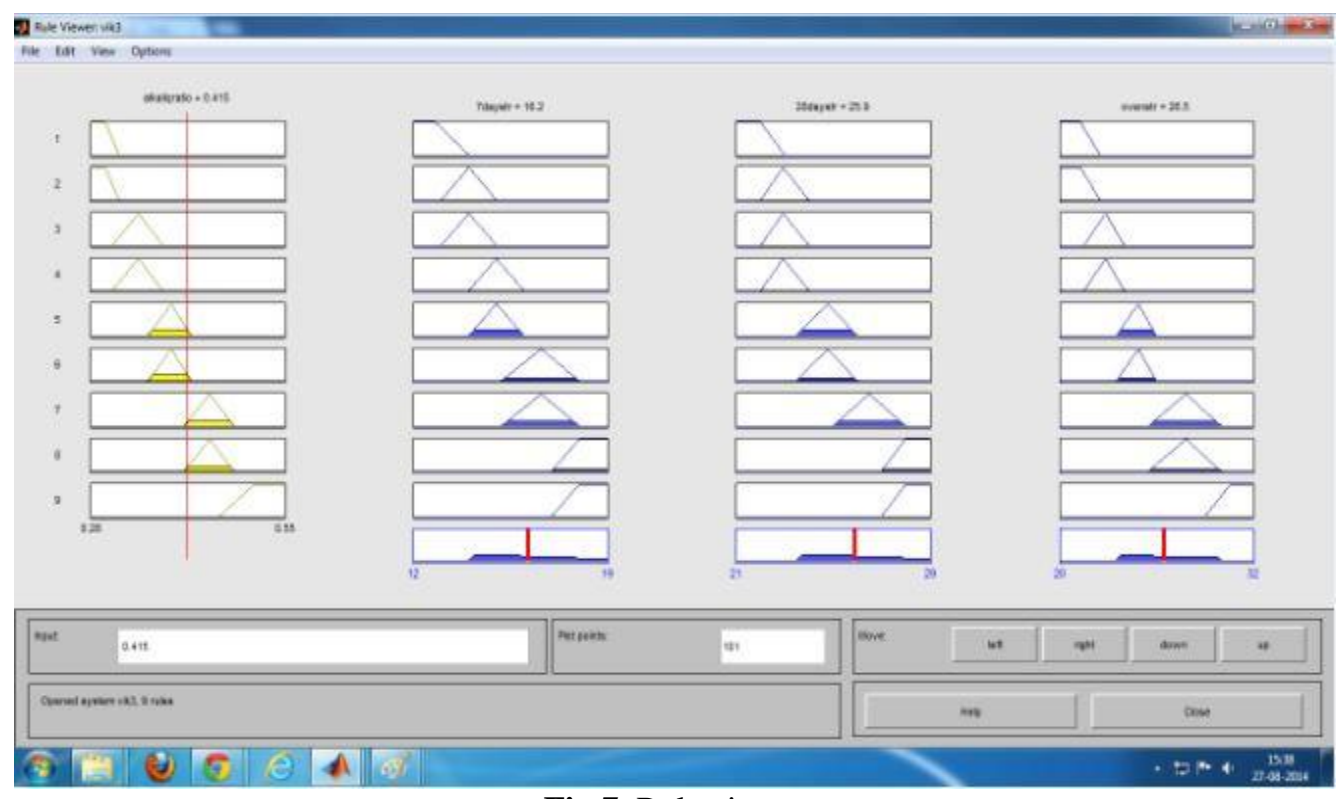

Fig.7. Rule viewer 


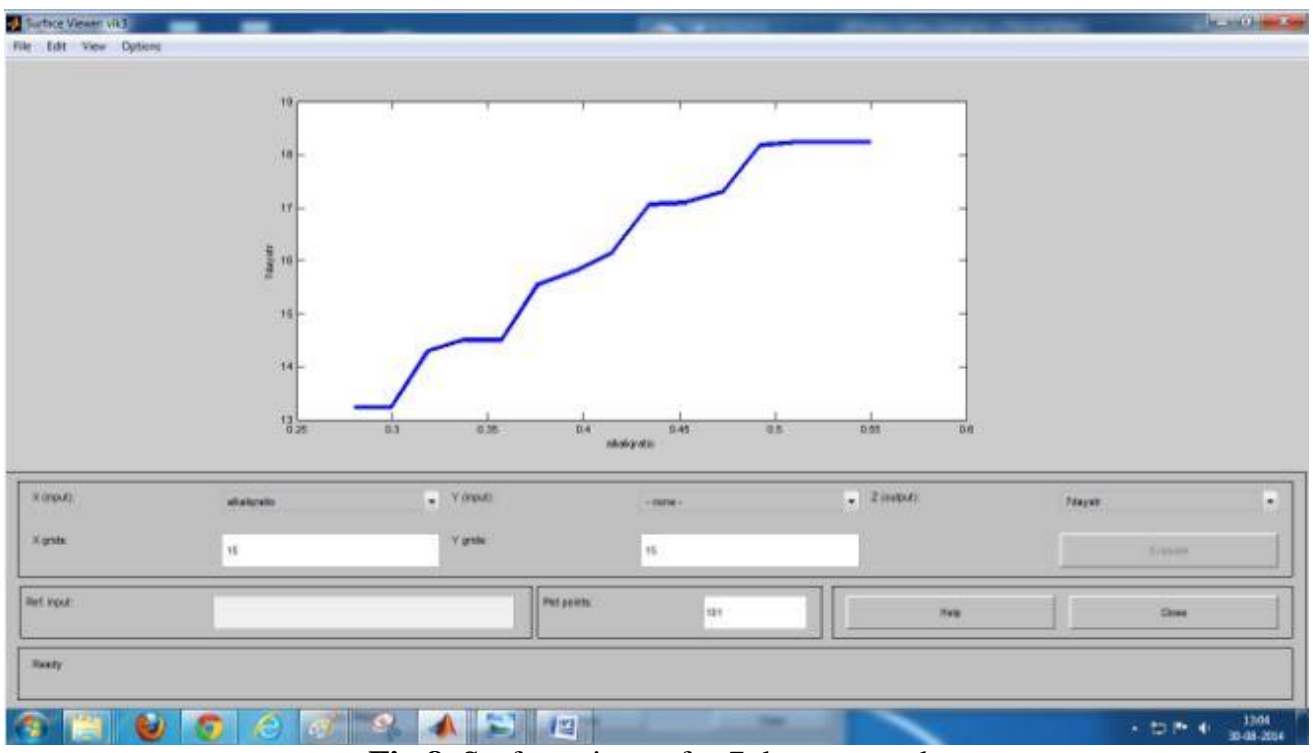

Fig 8. Surface viewer for 7 days strength

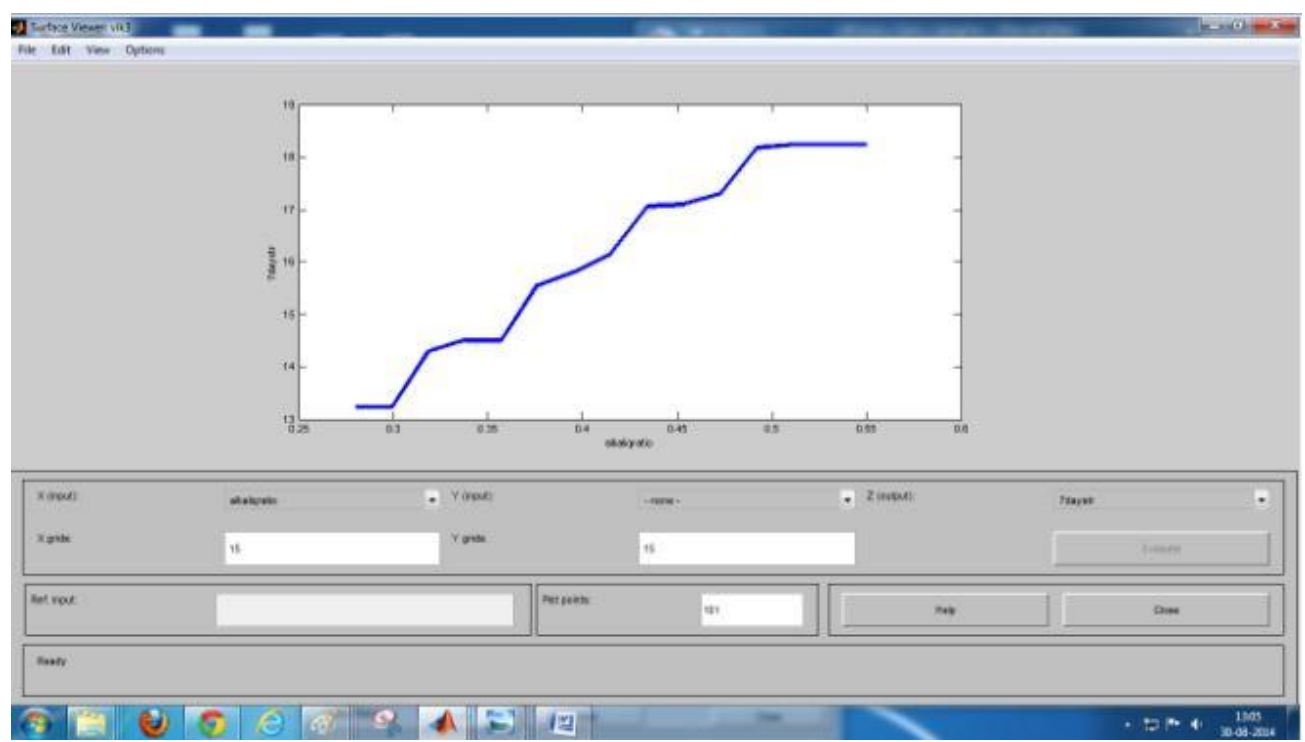

Fig .9. Surface viewer for 28 days strength

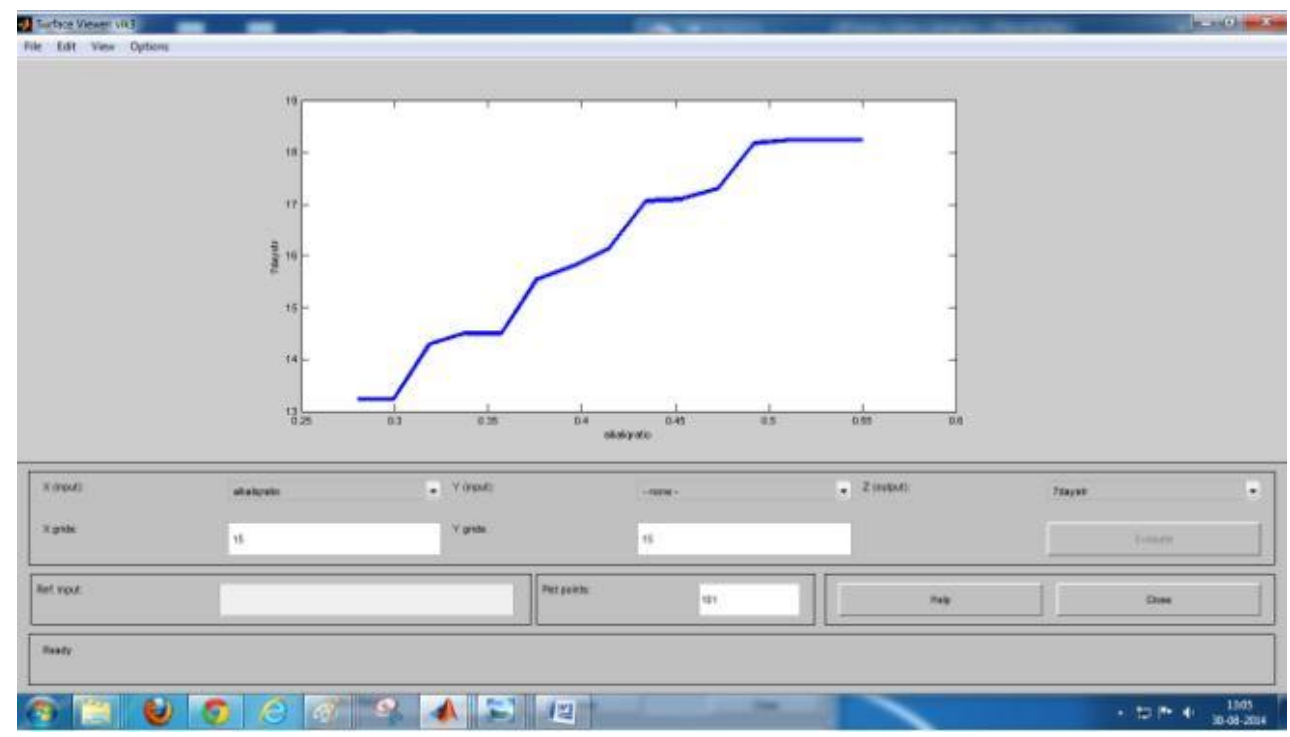

Fig 10. Surface viewer for oven cured sample 


\section{RESULTS AND DISCUSSION}

Table 3 Average Compressive strengths for different chemical ratios for $150 \mathrm{~mm} \times 150 \mathrm{~mm} \times 150 \mathrm{~mm}$ specimens.

\begin{tabular}{|l|l|l|l|}
\hline $\begin{array}{l}\text { Alkaline } \\
\text { liquid } \\
\text { Ratio }\end{array}$ & $\begin{array}{l}7 \text { days } \\
\text { compressive } \\
\text { strength }\end{array}$ & $\begin{array}{l}\text { 28days } \\
\text { compressive } \\
\text { strength }\end{array}$ & $\begin{array}{l}\text { Oven } \\
\text { strength }\end{array}$ \\
\hline 0.5 & 18.75 & 28.55 & 31.52 \\
\hline 0.45 & 17.1 & 27.07 & 28.75 \\
\hline 0.4 & 15.8 & 24.7 & 25 \\
\hline 0.35 & 14.5 & 23.2 & 23 \\
\hline 0.3 & 13.2 & 22 & 21.3 \\
\hline
\end{tabular}

Experimental results clearly shows that when chemical ratio decreases from 0.5 to 0.3 , the 7 day strength decreases from 18.75 to $13.2 \mathrm{MPa}, 28$ day strength decreases from 28.55 to $22 \mathrm{MPa}$ and Oven strength is observed to be decreased from 31.52 to $21.3 \mathrm{MPa}$
Table 4 Comparision of 7 day, 28 day and oven strength

\begin{tabular}{|l|l|l|}
\hline $\begin{array}{l}\text { Alkaline liquid } \\
\text { Ratio }\end{array}$ & $\begin{array}{l}7 \text { day strength in \% } \\
\text { age of 28 day } \\
\text { strength (a) }\end{array}$ & $\begin{array}{l}\text { oven strength } \\
\text { in \% age of 28 } \\
\text { day strength } \\
\text { (b) }\end{array}$ \\
\hline 0.5 & 65.67 & 110.40 \\
\hline 0.45 & 63.16 & 106.206 \\
\hline 0.4 & 63.96 & 101.21 \\
\hline 0.35 & 62.5 & 99.137 \\
\hline 0.3 & 60 & 96.81 \\
\hline
\end{tabular}

By considering 28 day strength as the base strength, 7 day strength as a \% age of 28 day strength and oven strength as a $\%$ age of 28 day strength values are calculated and shown in the Table 4 and the comparison of 7 day, 28 day and oven strengths are shown in the form of bar graph and is shown in the fig11 below.

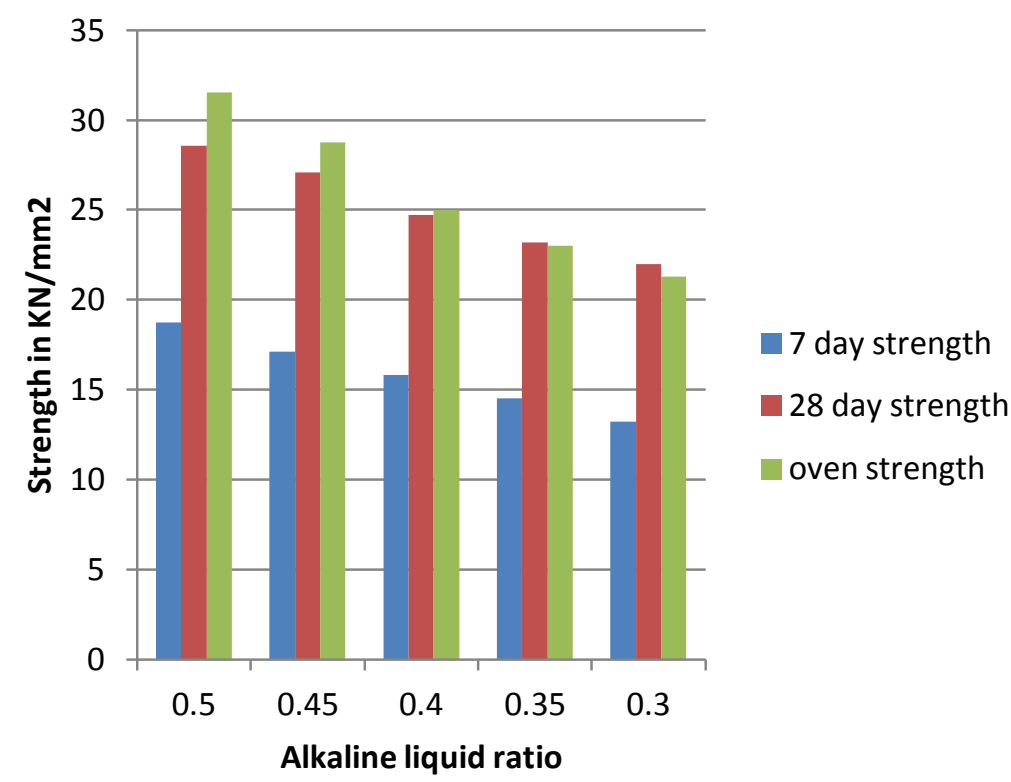

Fig. 11. comparision of strengths of 7 day, 28 day and oven compressive experimental strengths.

From the bar graph, it is clearly seen that 28 day strength and oven strength are almost equal. The compressive strengths can be clearly seen in the above figure.

\section{Fuzzy Algorithm for Development of model}

Fuzzy set theory was developed by lofi zadeh in 1965 to deal with the imprecision and uncertainity that is often present in real world application. In 1974 Mamdani by applying Zadeh's theories of linguistic approach and fuzzy inference, successfully used the 'IF THEN' rule on the automatic operating control of stream generator. It needs only to set a simple controlling method based on engineering experience. Therefore, this method is particularly useful in complicated structural systems. Fuzzy logic has been developing since 1965 and become most successful in application.
In this study, the fuzzy logic model is developed to replace the experimental results. Half of the results are used for testing and training and remaining are used for validating the results. The fuzzy-based algorithm model is deviced by using the fuzzy logic tool box in MATLAB. The input and output variables for fuzzy logic model are divided. The fuzzy logic model has one input parameter (alkaline-liquid ratio) and three output parameters (7day, 28day and oven compressive strengths). The fuzzy rules were written for developing model for compressive strength of concrete. The one of fuzzy logic rules is:

If (alkaliqratio is low) then (7daystr is med)(28datstr is high)(ovenstr is vhigh)(1) 


\section{Fuzzy Logic Results}

In this study, compressive strength prediction was done using fuzzy logic. The fuzzy algorithm was devised for decreasing alkaline liquid ratio. The results of the developed fuzzy model, experimental results for compressive strength and their percentage variation are given in table No. 5 to 7 . and their graphs are shown in figures 12,14 and 16 respectively. Bar graphs comparing experimental and theoretical results for 7 day, 28 day and oven strength for each alkaline liquid ratio are shown in the fig 13,15 and 17 respectively.

The number of samples initially analyzed through fuzzy logic was 75. The results of compressive strength of concrete of fuzzy model were similar to experimental results and found remarkable close to each other. Average absolute percentage error is measured for the fuzzy logic model.

\subsection{7 day compressive strength results}

Table 5 Experimental and theoretical results for 7day compressive strength

\begin{tabular}{|l|l|l|l|}
\hline $\begin{array}{l}\text { Alkaline } \\
\text { liquid Ratio }\end{array}$ & $\begin{array}{l}\text { Experimental } \\
\text { Results KN/mm }\end{array}$ & $\begin{array}{l}\text { Theoritical } \\
\text { Results } \\
\mathrm{KN} / \mathrm{mm}^{2}\end{array}$ & $\begin{array}{l}\% \\
\text { Error }\end{array}$ \\
\hline 0.5 & 18.75 & 18.2 & 2.93 \\
\hline 0.45 & 17.8 & 17.1 & 3.94 \\
\hline 0.4 & 15.51 & 15.8 & -1.87 \\
\hline 0.35 & 14.3 & 14.5 & -1.40 \\
\hline 0.3 & 13.64 & 13.2 & 3.23 \\
\hline
\end{tabular}

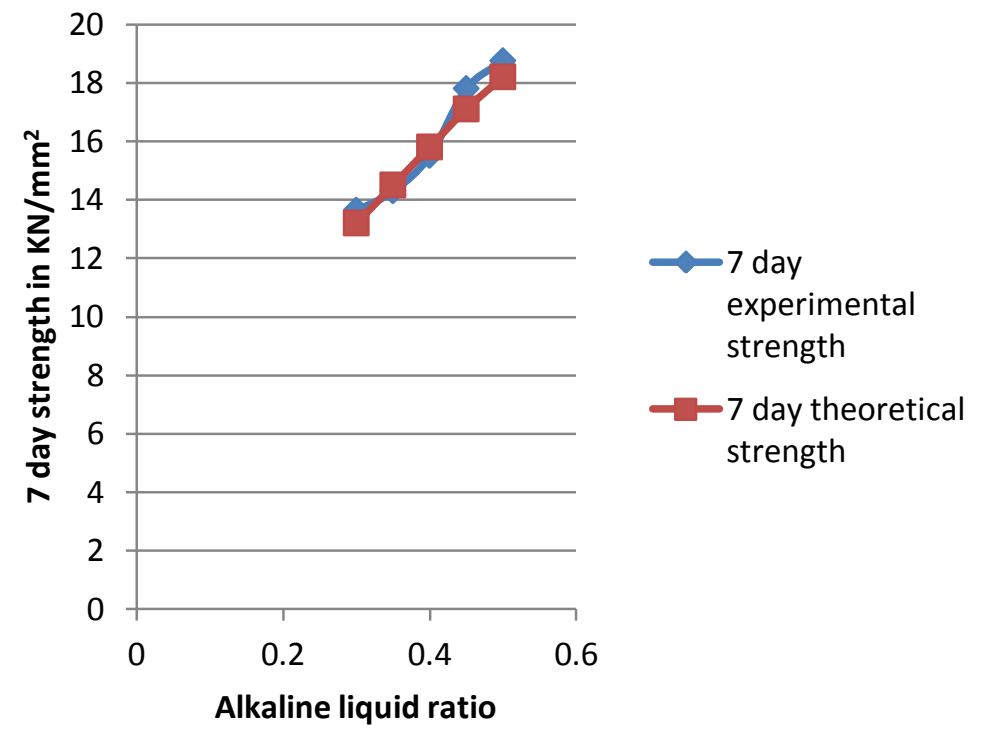

Fig 12. Comparision of 7 day experimental strength with the 7 day model strength.

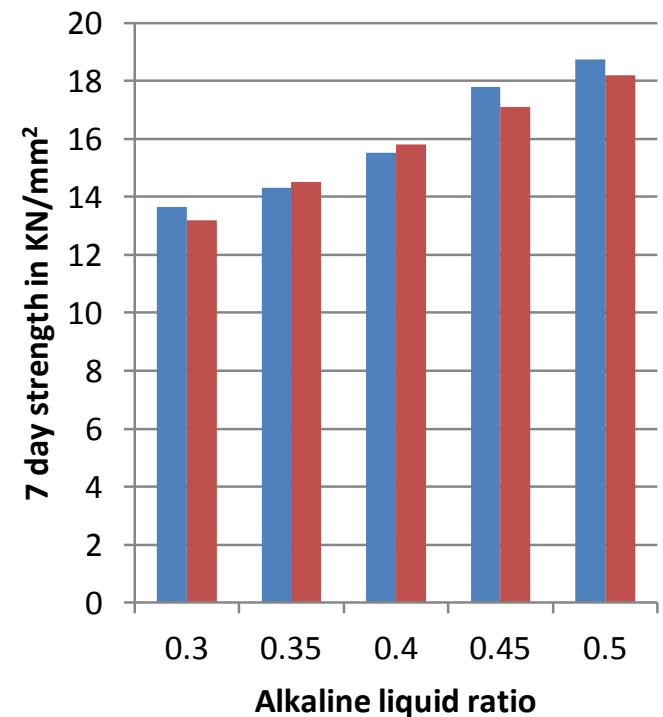

7 day experimental strength

7 day theoretical strength

Fig 13. Bar graph comparing experimental and theoretical results for 7 day strength 


\subsection{Day Compressive Strength Results}

Table 6. Variation of 28 day Compressive strength and theoretical results

\begin{tabular}{|l|l|l|l|}
\hline $\begin{array}{l}\text { Alkaline } \\
\text { liquid ratio }\end{array}$ & $\begin{array}{l}\text { Experimental } \\
\text { Results } \\
\mathrm{KN} / \mathrm{mm}^{2}\end{array}$ & $\begin{array}{l}\text { Theoritical } \\
\text { Results } \\
\mathrm{KN} / \mathrm{mm}^{2}\end{array}$ & $\begin{array}{l}\text { Error } \\
\text { Err }\end{array}$ \\
\hline 0.5 & 28.55 & 28.2 & 1.23 \\
\hline 0.45 & 27.07 & 27 & 0.26 \\
\hline 0.4 & 24.7 & 24.8 & -0.4 \\
\hline 0.35 & 23.2 & 23 & 0.86 \\
\hline 0.3 & 22 & 22.2 & -0.91 \\
\hline
\end{tabular}

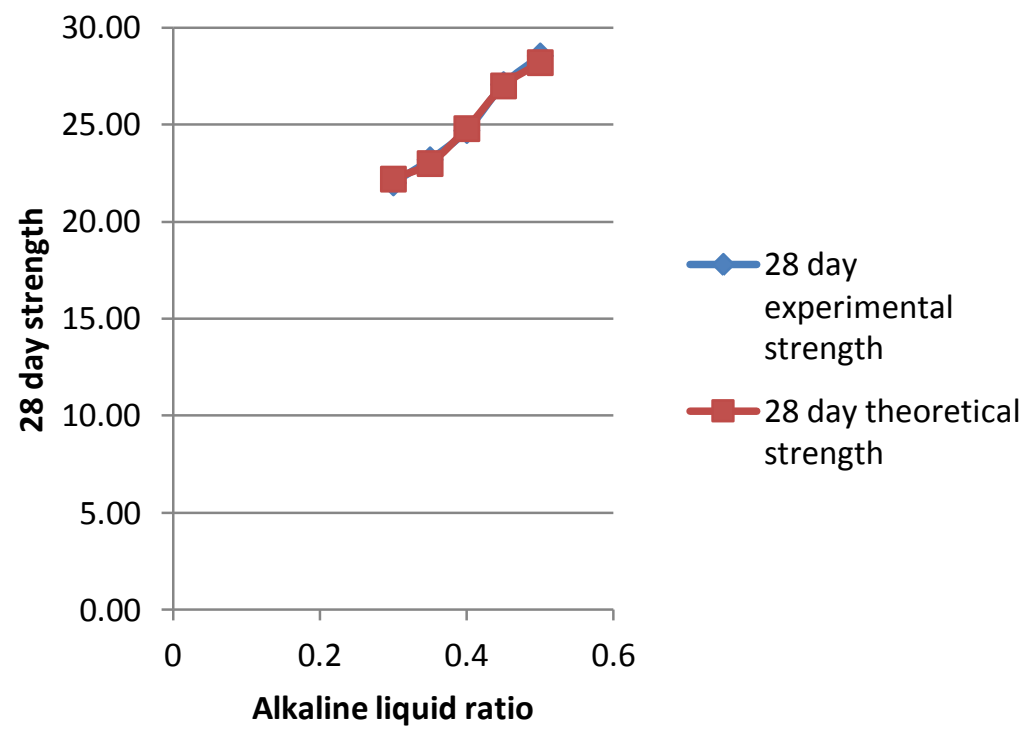

Fig 14 Comparision of 28 day experimental strength with the 28 day model strength.

For the increase in alkaline liquid ratio from 0.3 to 0.5 , the compressive strength is observed to increase from 22 to $28.55 \mathrm{MPa}$ for experimental results and from 22.2 to 28.2 for theoretical results. The \% age errors between experimental and theoretical results are shown in the Table.

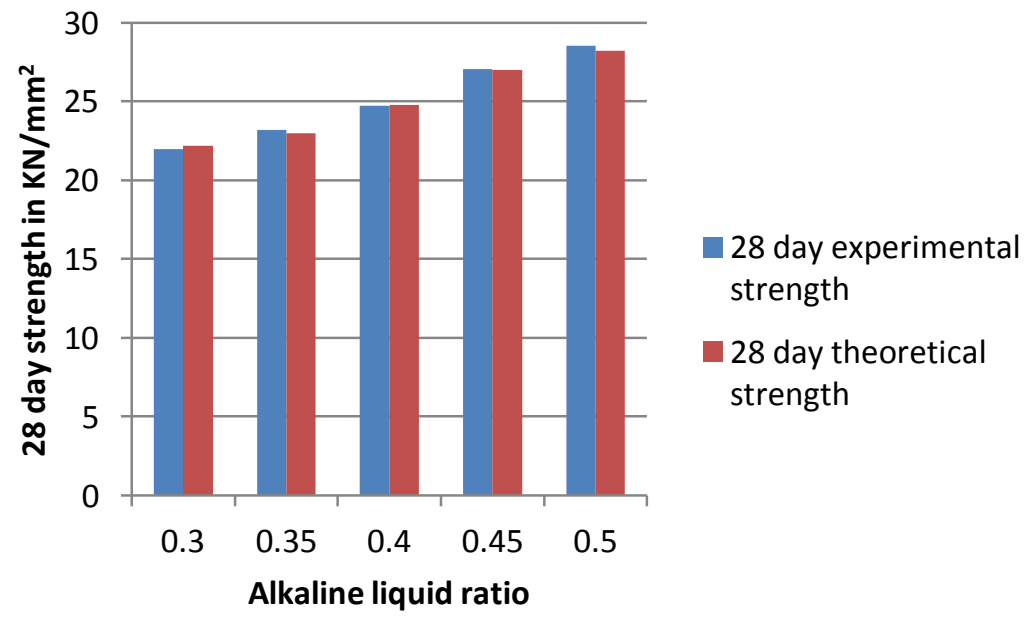

Fig 15. Bar graph comparing experimental and theoretical results for 28 day strength

For the decrease in alkaline liquid ratio from 0.5 to 0.3 , the 28 day compressive strength is observed to be decreased. The experimental and theoretical strength differences can be clearly observed from the above bar graph. 


\subsection{Oven Compressive Strength Results}

Table 7. Variation of Oven cured samples Compressive strength and theoretical results

\begin{tabular}{|l|l|l|l|}
\hline $\begin{array}{l}\text { Alkaline } \\
\text { liquid Ratio }\end{array}$ & $\begin{array}{l}\text { Experimental } \\
\text { results } \\
\mathrm{KN} / \mathrm{mm}^{2}\end{array}$ & $\begin{array}{l}\text { Theoritical } \\
\text { Results } \\
\mathrm{KN} / \mathrm{mm}^{2}\end{array}$ & \% Error \\
\hline 0.5 & 31.52 & 30.8 & 2.284 \\
\hline 0.45 & 28.25 & 27.8 & 3.304 \\
\hline 0.4 & 25 & 24.8 & 0.869 \\
\hline 0.35 & 23 & 22.8 & 0.8695 \\
\hline 0.3 & 21.3 & 20.9 & 1.877 \\
\hline
\end{tabular}

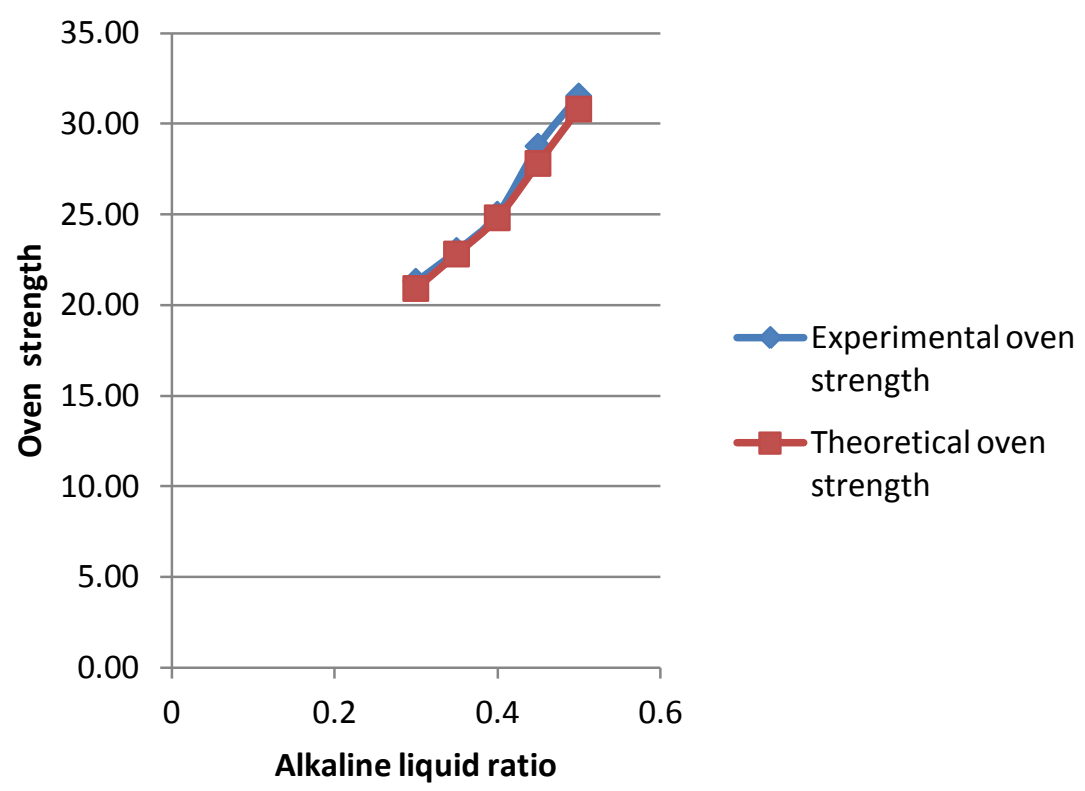

Fig 16 Comparision of oven experimental strength with the oven model strength.

For the increase in alkaline liquid ratio from 0.3 to 0.5 , the compressive strength is observed to increase from 21.3 to $31.52 \mathrm{MPa}$ for experimental results and from 20.9 to 30.8 for theoretical results. The $\%$ age errors between experimental and theoretical results are shown in the Table 6.10.

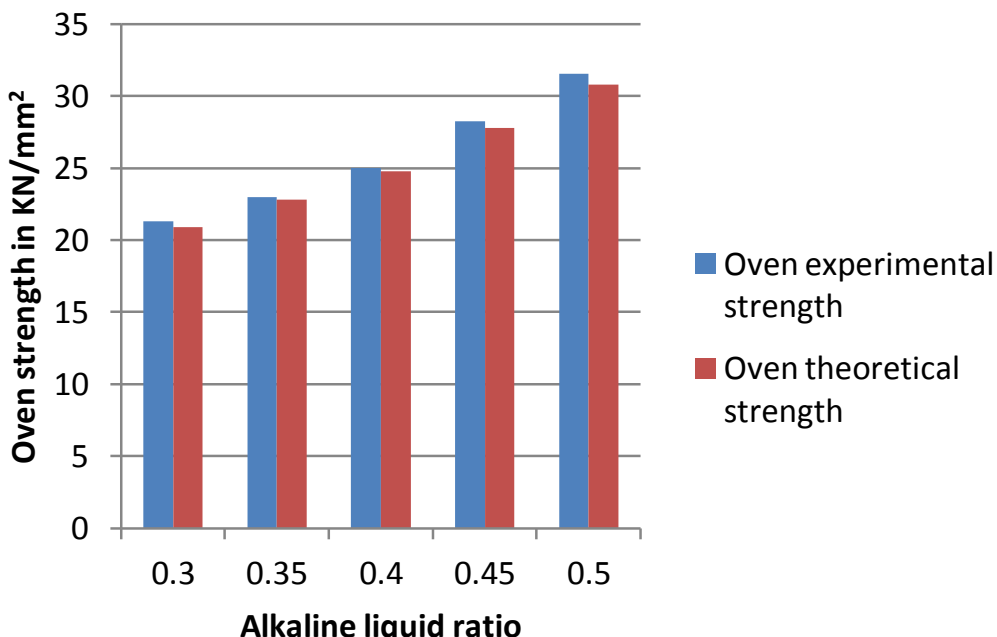

Fig 17. Bar graph comparing experimental and theoretical results for oven strength. 
For the decrease in alkaline liquid ratio from 0.5 to 0.3 , the oven compressive strength is observed to be decreased. The experimental and theoretical strength differences can be clearly observed from the above bar graph.

The theoretical model is prepared to replace the experimental work. Average absolute percentage error in between experimental and theoretical data clearly indicate that model perfectly replaced with the experimental work. Average Absolute Percentage error (AAPE) for Theoritical model for 7 day, 28 day and oven strengths are $2.674 \%$, $0.732 \%$ and $1.8268 \%$.

\section{Average Absolute Percentage Error (A.A.P.E) = $\frac{|E|}{\text { EXPERIMENTAL VALUES }}$}

Average Absolute percentage error for 7 day strength is $\frac{\sum|E 1|}{5}=2.674 \%$

Average Absolute percentage error for 28 day strength is $\frac{\sum|E 2|}{5}=0.732 \%$

Average Absolute percentage error for oven strength is $\frac{\sum|E 3|}{5}=1.8268 \%$

Table 8 Percentage error between theoretical and experimental results for different Alkaline liquid ratios

\begin{tabular}{|c|c|c|c|c|c|c|c|c|c|}
\hline \multirow{3}{*}{$\begin{array}{l}\text { Alkaline } \\
\text { liquid } \\
\text { ratio }\end{array}$} & \multicolumn{3}{|c|}{ Experimental results } & \multicolumn{3}{|c|}{ Theoretical results } & \multirow{2}{*}{\multicolumn{3}{|c|}{$\%$ age Error $\mathbf{E}$}} \\
\hline & \multicolumn{3}{|c|}{$\begin{array}{l}\text { Compressive strengths in } \\
\mathrm{MPa}\end{array}$} & \multicolumn{3}{|c|}{$\begin{array}{l}\text { Compressive strengths in } \\
\mathrm{MPa}\end{array}$} & & & \\
\hline & 7 day & 28 day & Oven & 7 day & 28 day & Oven & $\begin{array}{ll}7 & \text { day } \\
E_{1} & \end{array}$ & $\begin{array}{l}\text { 28day } \\
\mathrm{E}_{2}\end{array}$ & $\begin{array}{l}\text { Oven } \\
E_{3}\end{array}$ \\
\hline 0.5 & 18.75 & 28.55 & 31.52 & 18.2 & 28.2 & 30.8 & 2.93 & 1.23 & 2.284 \\
\hline 0.45 & 17.8 & 27.07 & 28.75 & 17.1 & 27 & 27.8 & 3.94 & 0.26 & 3.304 \\
\hline 0.4 & 15.51 & 24.7 & 25 & 15.8 & 24.8 & 24.8 & -1.87 & -0.4 & 0.8 \\
\hline 0.35 & 14.3 & 23.2 & 23 & 14.5 & 23 & 22.8 & -1.4 & 0.86 & 0.869 \\
\hline 0.3 & 13.64 & 22 & 21.3 & 13.2 & 22.2 & 20.9 & 3.23 & -0.91 & 1.877 \\
\hline
\end{tabular}

\section{CONCLUSION}

- $\quad$ For the increase in alkaline-liquid ratio from 0.3 to 0.5 , the 7 day compressive strength is observed to be increased from 13.64 Mpa to 18.75 Mpa.

- $\quad$ For the increase in alkaline-liquid ratio from 0.3 to 0.5 , the 28 day compressive strength is observed to be increased from $22 \mathrm{Mpa}$ to $28.55 \mathrm{Mpa}$.

- For the increase in alkaline-liquid ratio from 0.3 to 0.5 , the oven compressive strength is observed to be increased from 21.3 Mpa to 31.52 MPa.

- $\quad$ The 7 day strength is observed to be $63.058 \%$ of 28 day strength of Geopolymer concrete.

- $\quad$ The oven strength is observed to be $102.75 \%$ of 28 day strength of Geopolymer concrete.

- The percentage errors between experimental and theoretical results in all the cases are very less i.e, less than $5 \%$. It indicates that the theoretical results are very close to experimental results.

- $\quad$ Average absolute Percentage error (AAPE) between experimental and theoretical result for 7 day compressive strength is $2.674 \%$.
- $\quad$ Average absolute Percentage error (AAPE) between experimental and theoretical result for 28 day compressive strength is $0.732 \%$.

- Average absolute Percentage error (AAPE) between experimental and theoretical result for oven compressive strength is $1.8268 \%$.

\section{REFERENCES}

[1] Vijai. K, Kumutha. R and Vishnuram B.G (2010) Effect of types of curing on strength of geopolymer concrete. Journal Vol.5(9), pp. 1419-1423

[2] Huntzinger and Eastmon (2009) A life-cycle assessment of Portland cement manufacturing: comparing the traditional process with alternative technologies. Journal of Cleaner Production (2008) $1-8$

[3] N.A.Lloyd and B.V.Rangan (2009) Fly Ash-Based Geopolymer Concrete. Conference Paper. pp 68-106.

[4] Cheema et al (2009) Geopolymer Concrete with Fly Ash. Second International Conference on Sustainable Construction Materials and Technologies. Volume 3, pp. 1493-1504 
[5] Meltem Ozturan [2008] Application of Fuzzy-neural networks in multi-ahead forecast of stock price. African Journal of Business Management Vol. 4(6), pp. $\quad 903-914$

[6] Fahn oscan [2008] An efficient bi-objective personnel assignment algorithm based on a hybrid particle swarm optimization model. Volume 37 Issue 12, December Pages 7825-7830

[7] Xu and Van Deventer (2006) Strength and Setting Times of Low Calcium Fly Ash-based Geopolymer Mortar. Vol. 2, No.4, July.

[8] Basyigit [2005] A model of adaptive neural-based fuzzy inference system (ANFIS) for prediction of friction coefficient in open channel flow. Scientific Research and Essays Vol. 6(5), pp. 1020-1027

[9] Palomo (2005) Strength and Setting Times of Low Calcium Fly Ash-based Geopolymer Mortar. Vol. 2, No.4, July .

[10] Gourley and Johnson (2005) Paper presented at the Materials 2003 Conference: Adaptive Materials for a Modern Society, Sydney. 'Gourley, J. T., \& Johnson, G. B.

[11] Hardjoto and Rangan [2004] Compressive Strength of Low Calcium Fly Ash GeopolymerConcrete- A Review.Vol 2, No. 4 July.

[12] Van Jaarsveld (2003) Eco-efficient Construction and Building Materials. Vol 2, No. 4.

[13] Chen and Chiu (2003) "Fire resistant Geopolymer produced by Granulated Blast Furnace Slag". Minerals Engineering 16(3); 205-210.

[14] Van Jaarsveld (2002). The potential use of geopolymeric materials to immobilise toxic metals. Part I Theory and applications, Minerals Engineering, Vol. 10 (7), 1997, pp. 659-669.

[15] Van Jaarsveld (2002). The potential use of geopolymeric materials to immobilise toxic metals. Part I Theory and applications, Minerals Engineering, Vol. 10 (7), 1997, pp. 659-669.

[16] Teixeira-Pinto et al (2002) Di xue qian yuan, Volume 12, Issues 1-2

[17] Barbosa (2000) International Concrete Abstracts Portal. (ISSN 2250-2459, ISO 9001:2008 Certified Journal, Volume 4, Issue 4, April.

[18] Palomo (1999) Strength and Setting Times of Low Calcium Fly Ash-based Geopolymer Mortar. Vol 2, No. 4 July

[19] Barbosa (1999) International Concrete Abstracts Portal. (ISSN 2250-2459, ISO 9001:2008 Certified Journal, Volume 4, Issue 4, April.)

\section{BIOGRAPHIES}

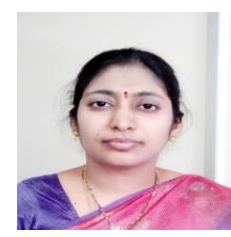

Mrs. D. Annapurna is Assistant Professor of Civil Engineering Department, University College of Engineering, Osmania University, Hyderabad. She published more than 10 papers in National and International

Conferences. She has over 10 years of teaching experience.

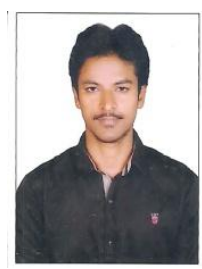

Mr.Vikas is a M.E. Research scholar in Civil Enineering Department, UCE, OU, Hyderabad. 